\title{
Diverse views show pathways to improvement
}

\author{
Recent updates to the $\mathrm{NIH}$ clinical trials policies have caused a heated debate led by affected scientists. By \\ broadening the debate to include diverse stakeholders within and outside the United States, we learn that the \\ steps the NIH takes are in the right direction, but further adjustments are needed to ensure that the policy's \\ goals are met.
}

A 11 commentators and correspondents who expressed their opinions in this focus issue share the sentiment that scientific research will benefit from embracing measures to improve robustness and public availability of research findings ${ }^{1}$. Within the diversity of views, there is a consensus regarding the high value of the goals of the new National Institutes of Health (NIH) policies, according to which all health-related studies involving experimental manipulations of humans are now classified as clinical trials: increasing transparency, accountability and stewardship of science ${ }^{1}$.

Given this shared concern and common values, what is there left to debate?

The contributions by external stakeholders and affected parties show that there are fundamental issues that still need to be addressed for the success of this policy. Concerns about support, preparation, fairness and foresight should be addressed to make this policy work for the research community.

Changes in regulation that increase demands on researchers - however justified - require changes in the support structure, to avoid stalling the scientific process and impairing individual careers ${ }^{2,3}$. And this support needs to be in place in advance. Practicalities such as whether the online grant-submission system can handle the new requirements ${ }^{4}$, and why established platforms are not being relied upon ${ }^{5}$, raise understandable concerns regarding whether the implementation of the policy was sufficiently well planned. Is the system prepared to deal with the next round of grant applications? Reassuringly, some concerns, such as the apprehension towards changes to grant evaluation committees, are assuaged in the Q\&A between Jeremy Wolfe (immediate past president of the Federation of Associations of Behavioral and Brain Sciences) and Michael Lauer of the $\mathrm{NIH}^{3}$.

On a broader level, commentators have raised questions about the fairness of implementing high standards for a subsection of research when the ultimate goals of transparency and accountability are equally necessary across all disciplines. Will selectively implementing requirements contribute to a fair research environment across all disciplines, or will it lead to double standards? ${ }^{6}$ This could, for example, be the case if different fields are treated differently by the same entity, or through differences in the regulatory standards different funders and institutions apply to the same field. Surely, the intention should be to create a fair research environment across all disciplines. For goals applicable to all disciplines, we should expect the same high standards to hold across the board ${ }^{5}$.

Broad application of uniform standards pertains not only to comparisons with non-human research, but also to types of human research that are currently excluded from the new requirements - for instance, human research that does not involve an intervention. And big-data approaches, which are being utilized to an ever greater extent to not only observe but also manipulate human behaviour ${ }^{6}$. With the present changes focused only on a subsection of human research, the NIH may be missing a chance to future-proof their funding policy.

However, these diverse perspectives can also be reassuring and point to solutions.

The history of the implementation of the Clinical Trials Directive in the European Union shows that concerns about the speed of change are common - but that adoption can become a welcome norm in the long run $^{7}$. In other words, there is nothing new, or unreasonable, about the policy: clinical research (in the 'traditional' sense) has successfully navigated such regulatory processes by funders and journals over the past two decades, leading to an increase in its robustness, transparency and credibility.

Different European countries have chosen different paths to address these issues; in the Netherlands, for example, independent governmental institutions, external stakeholders and the scientific community across different disciplines are in a close dialogue to set the regulations and determine the future of health research on a national level ${ }^{8}$.

What is clear in these examples is that regulatory frameworks and incentive structures are integral to the successful change of scientific practises. Within the current structures, science is unlikely to selfcorrect: adoption of robust practises has been shown to be neither rapid nor universal ${ }^{9,10}$. Rewarding robust scientific practises, while essential and commendable, may not suffice without complementary regulations. This places a responsibility on stakeholders such as funders, employers and journals, to create well-designed policy structures. Internationally, funders and science regulators will be observing the developments in the United States closely, to devise their own strategies for the future, while journals have to be at the very least aware of the changes and adjust our practices to support the goals of robustness and transparency.

The public discussion around changes to NIH policies and funding of human research that involves health-related interventions achieved international visibility when more than 3,500 researchers signed an open letter opposing the changes ${ }^{11}$. In this focus issue, we see that listening to diverse voices who share expertise and experience will allow the debate to move on and focus on practicalities and opportunities. The concerns raised by these diverse stakeholders, some new to the debate, are important and should be considered as updates to the current policy. The opinions and expertise of directly affected and external stakeholders need to be taken into account to ensure the success of the NIH's important decision to contribute to an environment of robust, transparent scientific practices.

Published online: 22 January 2018 https://doi.org/10.1038/s41562-018-0304-9

\footnotetext{
References

1. Riley, W. T., Riddle, M. \& Lauer, M. Nat. Hum. Behav. https://doi. org/10.1038/s41562-017-0265-4 (2017)

2. Wolfe, J. M. \& Kanwisher, N. G. Nat. Hum. Behav. https://doi. org/10.1038/s41562-017-0262-7 (2017).

3. Wolfe, J. M. Nat. Hum. Behav. https://doi.org/10.1038/s41562 018-0303-x (2018)

4. Mayo-Wilson, E. \& Dickersin, K. Nat. Hum. Behav. https://doi. org/10.1038/s41562-017-0286-z (2018).

5. Mellor, D. T. \& Nosek, B. A. Nat. Hum. Behav. https://doi org/10.1038/s41562-018-0294-7 (2018).

6. Amunts, K. Nat. Hum. Behav. https://doi.org/10.1038/s41562018-0292-9 (2018)

7. Crawley, F. P. Nat. Hum. Behav. https://doi.org/10.1038/s41562018-0293-8 (2018)

8. van Gerven, J. M. A. \& Geurts, J. J. G. Nat. Hum. Behav. https:// doi.org/10.1038/s41562-018-0296-5 (2018).

9. Krumholz, H. M. \& Ross, J. A. Nat. Hum. Behav. https://doi. org/10.1038/s41562-018-0300-0 (2018).

10. Munafò, M. R. et al. Nat. Hum. Behav. 1, 0021 (2017).

11. Wolfe, J. et al. Open letter to NIH director Francis Collins (iPetitions, 2017); https://www.ipetitions.com/petition/openletter-nih-collins
} 